\title{
Factors affecting visual outcome in traumatic cataract and its associated ocular injuries - A hospital based study
}

\author{
Sofi IA ${ }^{1}$, Aziz $\mathbf{R}^{2}$, Wani $\mathbf{J S}^{3}$ \\ ${ }^{1}$ Dr Ishfaq Ahmad Sofi, Registrar, ${ }^{2}$ Dr Rakhshanda Aziz, Resident, ${ }^{3}$ Dr Junaid S. Wani, Professor; All are affiliated with \\ Postgraduate Department of Ophthalmology, Government Medical College, Srinagar, Jammu \& Kashmir, India.
}

Address for Correspondence: Dr Ishfaq Ahmad Sofi., Room no 402, Doctor's Hostel, opposite casuality block SMHS hospital, Karan Nagar, Srinagar, J \& K India. Email-drsofiishfaq@gmail.com

\begin{abstract}
Background: Ocular trauma is a major cause of visual impairment throughout the world, although little is known about the factors that affect the visual outcome in traumatic cataract in developing countries. Aims and Objectives: To find out the associated ocular injuries and the factors affecting final visual outcome of patients with traumatic cataract. Material Methods: This prospective hospital based study was conducted on 40 patients of traumatic cataract. Patients were managed with lens extraction and intraocular lens implantation. Regular follow up of patients was done and best corrected visual acuity and post operative complications were assessed at the end of six months. Results: Our study showed that majority $(50 \%)$ of patients were in the age group of $<20$ years with male preponderance. visual outcome was significantly better in younger age group $(<20 \mathrm{yrs})$ than the older group $(>20 \mathrm{yrs})(\mathrm{p}=0.03)$. There was no significant difference in final visual outcome of traumatic cataracts caused by penetrating or blunt trauma $(p=0.73)$. Corneal tear was most common associated ocular damage followed by uveitis, lens matter in anterior chamber. Conclusions: Age of the patient affects final visual outcome after surgical treatment of traumatic cataract but type of trauma (blunt / penetrating) had no significant effect on final visual outcome. Corneal tear was most common associated ocular damage.
\end{abstract}

Keywords:- Traumatic cataract, Visual Outcome, Best Corrected Visual Acuity, Ocular trauma.

\section{Introduction}

Ocular trauma is a major cause of monocular blindness and visual impairment throughout the world, although little is known about its epidemiology or associated visual outcome in developing countries [1]. Traumatic cataract is very common sequel of ocular trauma [2]. It may occur when natural lens is damaged either by a blunt or penetrating injury. The methods used to evaluate the visual outcome in eyes managed for traumatic cataracts and senile cataracts are similar [3], but the damage to other ocular tissues due to trauma may compromise the visual gain in eyes operated on for traumatic cataracts. Postoperative inflammation and corneal scar are common complication following traumatic cataracts, hampering visual outcome $[4,5,6,7,8]$. Other complications leading to decreased post operative vision are, secondary glaucoma,

Manuscript received $4^{\text {th }}$ April 2016

Reviewed: $16^{\text {th }}$ April 2016

Author Corrected: $28^{\text {th }}$ April 2016

Accepted for Publication $16^{\text {th }}$ May 2016 pupillary capture, posterior capsular opacification and retinal scar [4]. The aim of this study was to find out the associated ocular injuries and visual outcome of patients with traumatic cataract along with their demographic features and modes of trauma.

\section{Aims and objectives}

The aim of this study was to find out the associated ocular injuries and the factors affecting final visual outcome of patients with traumatic cataract.

\section{Material and Methods}

This prospective study was carried out in the Department of Ophthalmology Government Medical College, Jammu. A comprehensive proforma was designed for this study. The study was conducted on patients of traumatic cataract as a result of ocular injury from blunt or penetrating trauma admitted in the 
department. Patients who gave consent and were cooperative and willing for the surgery were included. Personal information of all the patients was recorded. After admission to the hospital, detailed history was taken with particular reference to age, sex, and mode of injury, causes and activity at the time of injury. Preoperative assessment included: Best corrected visual acuity (BCVA) by snellen test-type, extraocular movements, fixation preferences, pupillary reflexes, slit lamp biomicroscopy of the anterior segment, applanation tonometry, dilated refraction, fundus examination with indirect ophthalmoscope. X-ray orbit was done to rule out any intra ocular radio opaque foreign body and B-scan when the optical medium was not clear enough to evaluate the posterior segment. Keratometry (Opposite normal eye was used in case of corneal surface irregularities), Intraocular lens power calculation and other relevant examinations and routine investigations were also done as well before surgery. All cases were subjected to surgery under local or general anaesthesia. The standard surgical procedure performed was SICS with posterior chamber IOL implantation, primary lens aspiration at the time of wound repair with primary or secondary IOL implantation. These surgical procedures were combined with other surgical procedures depending upon the need in individual cases. Post-operatively all patients were treated with topical steroids along with topical antibiotics and non steroidal anti-inflammatory drugs. Steroids were gradually tapered over next six weeks to two months. Patients were discharged with topical antibiotics, steroids and topical cycloplegics. Patients were called for regular follow up after three days, then once a week for next six weeks, monthly for next three months and thereafter, every three months. On follow up, visual acuity, IOP recordings, detailed slit lamp biomicroscopy to rule out any uveitis, intraocular lens decentration, synechiae, pupillary capture and posterior capsular opacification were done. Posterior segment evaluation was done with indirect ophthalmoscopy. This study was in accordance with the ethical standards of Declaration of Helsinki and was approved by the Ethical committee of the institution. A written informed consent was taken from all the participants. Forty cases that were admitted our institution were studied over a period of one and half year. Data was analysed by using Statistical Package of Social Sciences (SPSS) 12. Appropriate statistical tests were applied. All p-values in our study were two tailed and a value of $<0.05$ was taken as statistically significant.

\section{Results}

In the present study of 40 cases of traumatic cataract, demographic, etiological factors, type of trauma, morphology, associated ocular injuries, pre operative visual acuity, type of surgery and their role in post operative best corrected visual acuity and complications were assessed and analyzed. The age group ranged from 5 to 60 years. $50 \%$ cases were found in the age group of 5-20 years followed by $32.5 \%$ in age group $21-40$ years and $17.5 \%$ in the age group > 40 years. In the present study, out of 40 cases, $30(75 \%)$ were males and $10(25 \%)$ were females. The male female ratio was 3:1. Twenty five cases $(62.5 \%)$ had traumatic cataract due to penetrating trauma and $15(37.5 \%)$ patients had traumatic cataract due to blunt trauma. Out of 40 cases of traumatic cataract, 24 cases $(60 \%)$ had injury by wooden particles like stick, thorn and bow arrow. Metallic agents like iron rod, wire compass were responsible in 4 cases $(10 \%)$. Penetrating injury by stone was seen in 2 cases $(5 \%)$ and with glass piece in $4(10 \%)$ cases, rest by fire cracker, cricket ball and burst carbonated bottle. Maximum numbers of injuries were found to be related to agricultural and domestic activities like cutting of wood followed by thorn and iron wire $\{20$ cases $(50 \%)\}$. Industrial related activities were seen in $4(10 \%)$ cases. Iron was the most common etiological factor. Sports related activities like cricket ball, bow arrow and fire cracker were type of activity in $11(27.5 \%)$ cases and school related in $3(7.5 \%)$ cases. Maximum number of cases (60\%) was operated within the first three months following trauma. Only $10 \%$ cases presented more than $18^{\text {th }}$ months after trauma. Best Corrected Visual Acuity (BCVA) at the time of presentation is shown in Table 1. Traumatic cataract was associated with injuries to the other ocular structures as well like corneal tear in $25(62.5 \%)$ cases, uveitis in $11(27.5 \%)$ cases. Lens matter in anterior chamber was seen in 9 cases $(22.5 \%)$ [Table 2]. Almost all cases underwent cataract extraction by small incision cataract surgery with primary or secondary intraocular lens implantation but 3 cases remained aphake. Intraoperatively vitreous loss was seen in 3 cases $(7.5 \%)$ and hyphema in $2(5 \%)$ cases. Traumatic cataract extraction behaves differently as compared to otherwise normal cataract extraction and was associated with postoperative complications like Uveitis in $11(27.5 \%)$ cases, Posterior Capsular Opacification (PCO) in 12 (30\%), Corneal edema in 4 (10\%), Macular edema $3(7.5 \%)$, increased IOP in $3(7.5 \%)$ cases, Pupillary capture in $2(5 \%)$ and Hyphema in $2(5 \%)$ cases. Procedures like NdYAG laser capsulotomy was employed in the management of these post-operative complications. Final Best Corrected Visual acuity (BCVA) was assessed at the end of six months. Out of 40 cases, BCVA of 6/18-6/6 was seen in 28 cases (70\%), BCVA of 6/36- 6/24 in 8 cases (20\%) and 10\% cases had BCVA equal to or less than 6/60[Table 3]. 
Table 1: Best Corrected Visual Acuity (BCVA) at the time of presentation.

\begin{tabular}{|l|l|}
\hline Initial VA & Number of Cases $-\mathbf{n}(\boldsymbol{\%})$ \\
\hline$>6 / 60$ & $1(2.5)$ \\
\hline $1 / 60-6 / 60$ & $10(25)$ \\
\hline $\mathrm{CF}-1 / 2 \mathrm{~m}$ & $2(5)$ \\
\hline $\mathrm{HM}$ & $4(10)$ \\
\hline PL/PR & $23(57.5)$ \\
\hline Total & $40(100)$ \\
\hline
\end{tabular}

Table 2: Associated ocular injuries.

\begin{tabular}{|l|l|}
\hline Associated ocular damage & Number of patients - n (\%) \\
\hline Corneal tear & $25(62.5)$ \\
\hline Increased IOP & $6(15)$ \\
\hline Uveitis & $11(27.5)$ \\
\hline Lens matter in AC & $9(22.5)$ \\
\hline Hyphema & $3(7.5)$ \\
\hline PC Rent & $3(7.5)$ \\
\hline Vitreous loss & $3(7.5)$ \\
\hline
\end{tabular}

Table 3: Final Best Corrected Visual Acuity (BCVA) at 6 months.

\begin{tabular}{|l|l|}
\hline Final BCVA & Number of eyes - n $(\%)$ \\
\hline$<3 / 60$ & $1(2.5)$ \\
\hline $3 / 60-6 / 60$ & $3(7.5)$ \\
\hline $6 / 36-6 / 24$ & $8(20)$ \\
\hline $6 / 18-6 / 12$ & $21(52.5)$ \\
\hline $6 / 9-6 / 6$ & $7(17.5)$ \\
\hline Total & $40(100)$ \\
\hline
\end{tabular}

Table 4: Effect of Age group on final visual outcome.

\begin{tabular}{|l|l|l|l|l|}
\hline \multirow{2}{*}{ Age } & \multicolumn{2}{|l|}{ Final Visual Acuity (BCVA) } & \multirow{2}{*}{ Total n (\%) } \\
\cline { 2 - 5 } & $\mathbf{6 / 6}$ to 6/18 $\mathbf{n}(\mathbf{\%})$ & $\mathbf{6 / 2 4}$ to 6/60 n $\mathbf{( \% )}$ & $\mathbf{6 / 6 0} \mathbf{n}(\mathbf{\%})$ & $10(25)$ \\
\hline $0-10$ & 8 & 2 & 0 & $10(25)$ \\
\hline $11-20$ & 9 & 1 & 0 & $6(15)$ \\
\hline $21-30$ & 4 & 2 & 0 & $7(17.5)$ \\
\hline $31-40$ & 5 & 2 & 0 & $3(7.5)$ \\
\hline $41-50$ & 1 & 1 & 1 & $4(10)$ \\
\hline$>50$ & 1 & 3 & 0 & $40(100)$ \\
\hline Total & $28(70 \%)$ & $11(27.5 \%)$ & $1(2.5 \%)$ & \\
\hline
\end{tabular}

$(\chi 2=4.29, \mathrm{p}=0.03)$

Table 5: Effect of type of trauma on final visual outcome.

\begin{tabular}{|l|l|l|l|l|}
\hline Type of injury & \multicolumn{2}{|l|}{ Final visual acuity (BCVA) } & Total n (\%) \\
\hline Penetrating trauma & 18 & 6 & 1 & $25(62.5)$ \\
\hline Blunt trauma & 10 & 5 & 0 & $15(37.5)$ \\
\hline Total & $28(70)$ & $11(27.5)$ & $1(2.5)$ & $40(100)$ \\
\hline
\end{tabular}

Fisher's exact $\mathrm{p}=0.73$ 
Effect of age on final visual outcome: Visual acuity more than 6/18 was taken as good vision, between 6/24-6/60 as fair, less than $6 / 60$ as poor. In our study $50 \%$ of cases were below the age of 20 years, $85 \%$ of these had achieved good final visual outcome followed by cases in the age group of 21-40,69\% of which had achieved good final visual outcome followed by cases older than 40 years, $28.7 \%$ had achieved good final visual outcome [Table 4]. Statistical analysis has shown that visual outcome was significantly better in younger age group $(<20$ yrs $)$ than the older group $(>20$ yrs $)(\chi 2=$ $4.29, \mathrm{p}=0.03)$.

Effect of type of trauma on final visual outcome: In our study $62.5 \%$ cases had penetrating and $37.5 \%$ had blunt trauma. $72 \%$ of cases of traumatic cataract due to penetrating trauma had achieved good final visual outcome $(>6 / 18)$ followed by $66.6 \%$ of cases of traumatic cataract due to blunt trauma had achieved good visual outcome $(>6 / 18)$ [Table 5]. There was no significant difference in final visual outcome between penetrating and blunt trauma (Fischer's exact $p=0.73$ ).

\section{Discussion}

Injury to the eye represents a major threat to vision and this may happen to any individual at any age in any work place. Ocular trauma often leads to traumatic cataract along with damage to other ocular structures. Electrophysiological [9] and radio-imaging [10-12] investigations are important tools for assessing comorbidities associated with an opaque cataractous lens. Factors affecting final visual outcome after traumatic cataract surgery would be useful for ophthalmologists in such cases. Traumatic cataract was managed with lens extraction and intraocular lens implantation. Our study showed that most cases (50\%) of traumatic cataract were found in the younger age group (5-20 years) with male preponderance. Sethi et al. reported in their study that most of the patients affected were young patients and half of them were children [13]. Srivastava et al found in their study that males are more affected [14]. Other studies have also proved same findings [15-17]. In our study blunt trauma accounts for traumatic cataract in $37.5 \%$ and penetrating trauma in $62.5 \%$ of cases. Our results were consistent with the results obtained by Memon $\mathrm{MN}$ et al that penetrating trauma accounts for traumatic cataract in $68.3 \%$ [18], Synder A et al observed penetrating trauma in $78.6 \%$ of cases [19] and Staffieri SE et al observed $88 \%$ cases of traumatic cataract due to penetrating trauma [20] while Gogate P et al observed traumatic cataract in $48.8 \%$ of cases due to blunt trauma and $39 \%$ of cases due to sharp trauma [21]. In our study wooden material like stick, thorn was the major cause of traumatic cataract which matches closely with study of Memon $\mathrm{MN}$ et al [18] and Shah MA [22]. In our study $67.5 \%$ had total cataract which matches with study of Panda A et al which had $74 \%$ total cataract [23]. In our study soft cataract was noticed in $22.5 \%$ which is consistent with the study of Shah MA et al in their study showed $59.9 \%$ patients had white soft cataract with ruptured anterior capsule followed by $26.6 \%$ had total cataract [22]. In our study more than half of patients had pre- treatment best corrected visual acuity of light perception only which is consistent with study of Ahmed $\mathrm{N}$ et al [24] where half of patients had visual acuity of hand movement and with study of Kumar S et al [25] where maximum patient had visual acuity of light perception only. In our study, Corneal tear was most common associated ocular damage followed by uveitis, lens matter in anterior chamber. Other studies also had corneal damage as most common associated ocular injury in ocular trauma cases [26]. In the present study, time interval between trauma and cataract surgery ranges from same day to 10 years. Maximum patients $(60 \%)$ presented to the hospital and underwent cataract surgery within 3 months, $17.5 \%$ patients within 4-6 months, $10 \%$ patients were operated upon after 18 months, $7.5 \%$ patients within 7-12 months followed by $5 \%$ within 13-18th months. One (2.5\%) patient was operated for traumatic cataract 10 years after trauma while Eckstein $M$ et al in their study showed time interval between injury and cataract surgery ranged from 1- 60 weeks with mean interval was 10.4 weeks [27]. In our study $92.5 \%$ patients were safely rehabilitated with IOL implantation which is consistent with the study of Panda A et al as they put IOL in $89.2 \%$ of patients [23] and Gogate $\mathrm{P}$ et al in $90.2 \%$ of patients [21]. In our study, BCVA of 6/18-6/6 was seen in $70 \%$ cases after surgical treatment, 6/36- 6/24 in 20\% cases and $10 \%$ cases had BCVA equal to or less than 6/60. Sharma AK et al had $43.7 \%$ patients who had acheived visual acuity of $>6 / 18$ after surgery [26], Similarly Kumar $\mathrm{S}$ et al observed in their study that $50 \%$ of the cases had visual acuity better than $6 / 18$ after surgery [25]. Stenberg et al reported that the initial visual acuity and patient age were predictors [28] and Shah $\mathrm{M}$ et al observed that patient age was a predictor, but the initial visual acuity was not [29]. In our study, we observed that patient's age affects final visual outcome after surgical treatment of traumatic cataract but type of trauma (blunt / penetrating) had no 
significant effect on final visual outcome.

\section{Summary and Conclusion}

Traumatic cataract resulting from ocular trauma is a common cause of ocular morbidity, especially in young population. Most of the injuries occur by wooden particles like stick or thorn. Most injuries were related to agricultural and domestic activities. Almost all patients were safely rehabilitated with cataract extraction and IOL implantation and patient's age affects final visual outcome after surgical treatment of traumatic cataract but type of trauma (blunt / penetrating) had no significant effect on final visual outcome. Corneal tear was the most common associated ocular damage followed by uveitis, lens matter in anterior chamber. We recommend use of protective glasses while doing agricultural or industrial work.

Funding: Nil, Conflict of interest: None initiated.

Permission from IRB: Yes

\section{References}

1. Khatry SK, Lewis AE, Schein OD, Thapa MD, Pradhan EK, Katz $\mathbf{J}$ et al. The epidemiology of ocular trauma in rural Nepal. Br J Ophthalmol. 2004 Apr; 88(4):456-60.

2. Thakker MM, Ray S. Vision limiting complications in open globe injuries. Can J Ophthalmol. 2006 Feb; 41(1):86-92.

3. Kuhn F, Morris R, Witherspoon CD, Mester V. The Birmingham Eye Trauma Terminology system (BETT). J Fr Ophtalmol. 2004 Feb;27(2):206-10.

4. Bekibele CO, Fasina O. Visual outcome of traumatic cataract surgery in Ibadan, Nigeria. Niger $\mathbf{J}$ Clin Pract. 2008 Dec;11(4):372-5.

5. Koenig SB, Ruttum MS, Lewandowski MF, Schultz RO. Pseudophakia for traumatic cataracts in children. Ophthalmology. 1993 Aug;100(8):1218-24.

6. Mohammadpour M, Jafarinasab MR, Javadi MA. Outcomes of acute postoperative inflammation after cataract surgery. Eur J Ophthalmol. 2007 JanFeb;17(1):20-8.

7. Hemo Y, BenEzra D. Traumatic cataracts in young children. Correction of aphakia by intraocular lens implantation. Ophthalmic Paediatr $\quad$ Genet. 1987 Nov;8(3):203-7.

8. Awner S, Buckley EG, DeVaro JM, Seaber JH. Unilateral pseudophakia in children under 4 years. J Pediatr Ophthalmol Strabismus. 1996 Jul-Aug; 33(4):230-6.

9. Corbett MC, Shilling JS, Holder GE. The assessment of clinical investigations: The Greenwich Grading System and its application to electro diagnostic testing in ophthalmology. Eye (Lond) 1995;9( Pt $6 \mathrm{Su}$ ):59-64.

10. Segev Y, Goldstein M, Lazar M, Reider-Groswasser I. CT appearance of a traumatic cataract. AJNR Am J Neuroradiol. 1995 May;16(5):1174-5.

11. McWhae JA, Crichton AC, Rinke M. Ultrasound biomicroscopy for the assessment of zonules after ocular trauma. Ophthalmology.2003 Jul;110(7):1340-3.

12. Zhang Y, Zhang J, Shi S. Determination of posterior lens capsule status in traumatic cataract with BUltrasonography. Zhonghua Yan Ke Za Zhi. 1998 Jul;34(4):298-9.

13. Sethi MJ, Sethi S, Khan T, Iqbal R. Occurrence of ocular trauma in patients admitted in eye department Khyber teaching hospital Peshawar. J Med Sci. 2009; 17:106-09.

14. Srivastava U, Lalramhluri R, Rawat P, Bhaisare V. Clinical evaluation of post traumatic cataract in tertiary care hospital. International Journal of Scientific \& Research Publications. 2014 Oct;4(10):1-6.

15. Smith D, Wrenn K, Stack LB. The epidemiology and diagnosis of penetrating eye injuries. Acad Emerg Med. 2002 Mar;9(3):209-13.

16. Reddy AK, Ray R, Yen KG. Surgical intervention for traumatic cataracts in children: epidemiology, complications and outcomes. J AAPOS. 2009 Apr;13(2):170-79. doi: 10.1016/j.jaapos.2008.10.015.

17. Cillino S, Cassiccio A, Di Pace F, Pilliteri F, Cillino G. A five-year retrospective study of the epidemiological characteristics and visual outcomes of patients hospitalized for ocular trauma in a Mediterranean area. BMC Ophthalmol. 2008 Apr;22:86. doi: 10.1186/1471-2415-8-6. 
18. Memon MN, Narsani AK, Nizamani NB. Visual outcome of unilateral traumatic cataract. J Coll Physicians Surg Pak. 2012;22(8):497-500.

19. Synder A, Kobielska D, Omulecki W. Intraocular lens implantation in traumatic cataract. Klin Oczna 1999;101(5): 343-6.

20. Staffieri SE, Ruddle JB, Mackey DA. Rock, Paper and scissors? Traumatic pediatric cataract in Victoria 1992-2006. Clin Experiment Ophthalmol 2010 Apr;38(3):237-41. doi: 10.1111/j.1442-9071.2010. 02236.

21. Gogate P, Sahasrabudhe M, Shah M, Patil S, Kulkarni A. Causes, epidemiology, and long term outcome of traumatic cataracts in children in rural India. Indian J Ophthalmol. 2012 Sep-Oct;60(5):481-6. doi: 10.4103/0301-4738.100557.

22. Shah MA, Shah SM, Shah SB, Patel CG, Patel UA. Morphology of traumatic cataract: does it play role in final visual outcome. BMJ Open 2011; 1(1):000060 doi : 10.1136./ bmjopen -2011-000060.

23. Panda A, Kumar S, Das H, Badhu BP. Striving for the perfect surgery in traumatic cataract following penetrating trauma in tertiary care hospital in Eastern Nepal. J Nepal Med Assoc. 2007Jul-Sep;46(167):11925.
24. Ahmed N, Aziz T, Akram S. Visual outcome after primary IOL implantation for traumatic cataract. Pak J Ophthalmol. 2011; 27(3): 152-4.

25. Kumar S, Panda A, Badhu BP, Das H. Safety of primary intraocular lens insertion in unilateral childhood traumatic cataract. J Nepal Med Assoc. 2008;47(172):179-85.

26. Sharma AK, Aslami AN, Shrivastava JP, Iqbal J. Visual Outcome of Traumatic Cataract at a Tertiary Eye Care Centre in North India: A Prospective Study. J Clin Diagn Res. 2016 Jan;10(1):05-8. doi: 10.7860/ JCDR/2016/17216.7049.

27. Eckstein M, Vijayalakshmi P, Killedar M, Gilbert C, Foster A. Use of intraocular lenses in children with traumatic cataract in south India. Br J Ophthalmol. 1998 Aug;82(8):911-5.

28. Sternberg P Jr, de Juan E Jr, Michels RG, Auer C. Multivariate analysis of prognostic factors in penetrating ocular injuries. Am J Ophthalmol. 1984 Oct; 98(4):467-72.

29. Shah M, Shah S, Shah S, Prasad V, Parikh A. Visual recovery and predictors of visual prognosis after managing traumatic cataracts in 555 patients. Indian $\mathbf{J}$ Ophthalmol. 2011 May-Jun;59(3):217- 22. doi: 10.4103/0301-4738.81043.

\section{How to cite this article?}

Sofi IA, Aziz R, Wani JS. Factors affecting visual outcome in traumatic cataract and its associated ocular injuries - A hospital based study. Int J Med Res Rev 2016;4(5):839-844.doi: 10.17511/ijmrr.2016.i05.30. 